\title{
CAMINHOS PARA AS LÍNGUAS NA FRONTEIRA: POLÍTICAS LINGUÍSTICAS NO BRASIL
}

\author{
PATHS TO LANGUAGES ON THE FRONTIER: \\ LANGUAGE POLICIES IN BRAZIL
}

Luana Ferreira Rodrigues ${ }^{1}$ http://lattes.cnpq.br/8236254051650694 https://orcid.org/0000-0003-0732-7834

Enviado em: $12 / 03 / 2020$

Aceito em: 21/09/2020

\begin{abstract}
RESUMO: O presente artigo tem como objetivo trazer algumas considerações sobre as políticas públicas voltadas para as línguas em contexto de fronteira no Brasil, por meio da análise de leis e projetos desenvolvidos pelo Estado nos últimos anos, como o Programa Escolas Interculturais de Fronteira (PEIF), entre os anos de 2005 e 2015, em convênio entre o Ministério da Educação do Brasil e a Secretaria Educativa do Mercosul. Sob a ótica da Política Linguística e estudos realizados por pesquisadores como Calvet (2002), Oliveira (2016), Sagaz (2013), Berger (2015) e Paz (2016), pretende-se pensar a importância do planejamento linguístico e a posta em prática de políticas que visem a preservação das línguas e a difusão do plurilinguismo no contexto fronteiriço.
\end{abstract}

Palavras-chave: Políticas Linguísticas. Fronteiras. Programa Escolas Interculturais de Fronteira.

\begin{abstract}
The present article aims to bring some considerations about the public policies focused on languages in the border context in Brazil, through the analysis of laws and projects developed by the State in recent years, such as the Programa Escolas Interculturais de Fronteira (PEIF) between 2005 and 2015, in an agreement between the Brazilian Ministry of Education and the Mercosur Education Secretariat. From the perspective of Linguistic Policy and studies carried out by researchers such as Calvet (2002), Oliveira (2016), Sagaz (2013), Berger (2015) and Paz (2016), we intend to think about the importance of linguistic planning and the practice of policies aimed at the preservation of languages and the diffusion of multilingualism in the frontier context.
\end{abstract}

Keywords: Language Policies. Borders. Intercultural Border Schools Program.

\section{INTRODUÇÃO}

Ainda são incipientes no Brasil os estudos que focam as línguas nas fronteiras, em especial nas fronteiras da Região Norte do país. Partindo dessa premissa, serão apresentadas nos três tópicos principais deste artigo considerações sobre o planejamento linguístico e políticas linguísticas desenvolvidas pelo Estado, passando por uma breve exposição da ausência de legislação que verse sobre as especificidades da educação em contexto fronteiriço, em especial sobre as línguas que fazem parte do repertório linguístico dos falantes dessas comunidades. Por último, se discute a principal ação para a gestão das línguas em contexto fronteiriço, o surgimento do Programa Escolas Interculturais (bilíngues) de Fronteira (doravante PEIF) como parte das políticas de integração

\footnotetext{
${ }_{1}$ Professora Assistente de Língua Espanhola, na Faculdade de Letras da Universidade Federal do Amazonas. Mestre em Língua e Cultura pela Universidade Federal da Bahia. Atualmente é doutoranda do Programa de Pós-Graduação em Linguística da Universidade Federal de Santa Catarina e bolsista da Fundação de Amparo à pesquisa do Estado do Amazonas- FAPEAM. Este trabalho se insere nos eixos de pesquisa Cátedra UNESCO em Políticas Linguísticas para o Multilinguismo, sob a coordenação do Prof. Dr. Gilvan Müller de Oliveira.
} 
entre os países participantes do Mercosul apontando para a necessidade de manutenção do programa e sua ampliação rumo à inclusão das diversas línguas que coabitam esses espaços.

\section{PLANEJAMENTO LINGUÍSTICO, POLÍTICAS LINGUÍSTICAS E FRONTEIRAS: BREVES CONSIDERAÇÕES}

Nos últimos anos vêm crescendo o número de pesquisas sobre as mais diversas situações linguísticas sob a ótica da Política Linguística ou Politologia (Calvet, 2002), a qual pode ser definida como um:

conjunto de decisões que um grupo de poder, sobretudo um Estado (mas também uma Igreja ou outros tipos de Instituições de poder menos totalizantes) toma sobre o lugar e a forma das línguas na sociedade, e a implementação destas decisões. (OLIVEIRA, 2004, p.38)

A Política ou Politologia Linguística tem como objeto as intervenções sobre as situações linguísticas, feitas através da análise das políticas e do planejamento linguístico que são definidos por Oliveira (2004, p.38) como:

propostas para modificar a realidade lingüística - do status de uma língua em relação a outra, ou de aspectos da sua forma- e se referem ao futuro da relação entre as línguas. Um processo de planificação lingüística posta em marcha passa a ser uma política lingüística. As políticas lingüísticas podem ser 'in vivo', quando decididas e implementadas em meio às atribulações políticas em geral, ou 'in vitro', quando seu planejamento e execução se dão de forma separada e seqüencial, em geral de forma minuciosa.

Nas definições propostas por Oliveira (2004) é possível observar o poder que determinados grupos exercem na instituição das políticas linguísticas sobre uma determinada comunidade, levando aos conceitos de política in vivo e in vitro. Uma política in vivo leva em consideração a comunidade de fala onde essa política será implementada, enquanto que a política in vitro se refere àquelas que são instituídas de cima para baixo, ou seja, sem a participação da comunidade, tendo como agentes os pesquisadores nas universidades e o Estado, por exemplo.

Para intervir em uma situação linguística é necessário inicialmente analisá-la a fim de compreender o problema que se apresenta, levando em conta que o desenvolvimento de políticas voltadas para determinada situação linguística deve ser composta por três elementos que formam um tripé: as práticas linguísticas, as crenças e ideologias linguísticas e a gestão das línguas.

Assim, a heterogeneidade das situações linguísticas em um país plurilíngue e de território extenso como o Brasil, revela a necessidade de um planejamento que busque acolher e proteger as línguas e culturas das diversas comunidades, desde as línguas autóctones, às línguas de imigrantes do passado e do presente e línguas faladas nas fronteiras em contato com o português, como são o caso do espanhol, do francês, do holandês e do inglês.

Apesar de bem definidas e demarcadas as fronteiras brasileiras, o mesmo não pode ser dito sobre as fronteiras linguísticas entre o português e as línguas mencionadas anteriormente, uma vez que os limites de um Estado dificilmente coincidem com o alcance das línguas nos territórios vizinhos, conformando o que Berger define como territórios linguísticos:

esferas de uso das línguas, não somente as demarcadas pelo poder exercido via instrumentos legais ou por intermédio de instâncias governamentais, mas também por outros agentes e grupos que, no campo das relações, agem sobre os usos das línguas, demarcando espaços de controle e fronteiras relacionais entre os grupos que delas compartilham, de forma descontínua.

A fronteira carrega consigo territorialidades, ou seja, modos de dar significado a esse território por parte daqueles que nele vivem, envolvendo mais que uma questão política, mas também 
relações culturais e econômicas.

Fica nítido que a demarcação do território por parte do poder político do Estado não conflui necessariamente com os territórios linguísticos nas fronteiras, uma vez que as relações estabelecidas entre as diferentes comunidades de fala são construídas e demarcadas coletivamente sem que haja uma delimitação de onde começa e termina uma língua.

A fronteira vem sendo tema de estudos em áreas como a Geografia Política e são diversas as conceitualizações propostas pelos estudiosos, mas todas estão ligadas aos conceitos de Estado, linhas, zonas e limites, porém cabe sinalizar que a fronteira vai além da noção de zona limítrofe entre dois territórios, pois nela estão presentes grupos sociais que cohabitam esse espaço com suas línguas, culturas, crenças, organização social e econômica, conforme coloca Zientara (1989, apud LUNA, 2011, p.303):

\begin{abstract}
O fator constitutivo das fronteiras é sempre uma comunidade que consiste numa organização mais ou menos vasta, mais ou menos estável. Pode ser uma comunidade econômica que transforma a paisagem natural em paisagem cultural, ou uma comunidade política que, seguindo diversos caminhos, se desenvolve transformando-se de tribo em Estado como também uma comunidade de origem religiosa se pode organizar em Estado. A tendência em fazer coincidir as fronteiras lingüísticas, culturais e econômicas com as estatais, opõe-se sempre outra em sentido contrário, como tendência 'a diferenciação das sociedades e à ultrapassagem dos limites pelos próprios grupos.
\end{abstract}

Vemos a fronteira como um espaço de contato e de conflitos entre indivíduos sociohistoricamente construídos, cujas línguas se encontram em um jogo de forças, tendo as situações de bilinguismo ou plurilinguismo como parte fundamental entre os elementos constituintes da territorialidade desse espaço, em que o planejamento e a implementação de políticas linguísticas devem levar em consideração todas as idiossincrasias que caracterizam as zonas de fronteira e suas comunidades.

\title{
GESTÃO PÚBLICA DAS LÍNGUAS EM CONTEXTO FRONTEIRIÇO NO BRASIL
}

Com uma extensão de $15.719 \mathrm{~km}$, a fronteira brasileira se limita com países como Paraguai, Uruguai, Argentina, Bolívia, Peru, Colômbia, Venezuela, Guiana Francesa (território ultramarino francês), Suriname e Guiana Inglesa, revelando o caráter plural de culturas e línguas em contato nessa área.

O controle das fronteiras e a segurança nacional sempre foram uma preocupação desde o período imperial aos dias atuais, desta forma, além do disposto na Constituição de 1988, existem no Brasil leis e decretos que tratam de temas relacionados às suas fronteiras, conforme tabela 1 :

Tabela 1: Legislação sobre as fronteiras brasileiras

\begin{tabular}{|l|l|}
\hline Ano & Legislação \\
\hline 1946 & Decreto-Lei 9.760. Dispõe sobre bens e imóveis da União. \\
\hline 1955 & Lei 2.597. Zonas indispensáveis à Defesa do País. (Revogada pela Lei 6.634/79) \\
\hline 1964 & Lei 4.504. Estatuto da Terra. \\
\hline 1966 & Lei 4.947. Estabelece Normas de Direito Agrário. \\
\hline 1970 & $\begin{array}{l}\text { Decreto-Lei 1.135. Dispõe sobre a organização, competência e funcionamento do Conselho de Segu- } \\
\text { rança Nacional. }\end{array}$ \\
\hline 1975 & Decreto-Lei 1.414. Dispõe sobre as terras devolutas em “Faixa de Fronteira”. \\
\hline 1979 & Lei 6.634. Dispõe sobre a "Faixa de Fronteira”. \\
\hline 1979 & Lei 6.739 Matrícula e Registro de Imóveis Rurais. \\
\hline 1987 & Decreto-Lei 2.375. Revoga o Decreto-Lei 1.164/71 e dispõe sobre terras públicas \\
\hline 1991 & Lei 8.183. Organização e funcionamento do Conselho de Defesa Nacional. \\
\hline 1993 & Lei 8.629. Dispõe sobre o regulamento da Reforma Agrária. \\
\hline
\end{tabular}

https://periodicos.unifap.br/index.php/letras

Macapá, v. 10, n. 1, $1^{\circ}$ sem., 2020 


\begin{tabular}{|l|l|}
\hline 1998 & Lei 9.614. Lei do Abate. \\
\hline 1999 & $\begin{array}{l}\text { Lei 9.871. Estabelece prazo para as ratificações de concessões e alienações de terras feitas pe- } \\
\text { los Estados na "Faixa de Fronteira". }\end{array}$ \\
\hline
\end{tabular}

Fonte: Elaboração própria

É possível observar que o tratamento dado pela legislação brasileira ao tema das fronteiras visa a demarcação de terras e a segurança e monitoramento do território nacional, sem que haja ênfase a questões de ordem social e necessidades básicas da população como saúde e educação, uma vez que o contexto fronteiriço demanda um planejamento que difere das áreas urbanas devido as suas características estruturais, de localização e acesso, por exemplo.

Apesar de não haver cobertura nas legislações que versam sobre a Educação em contexto de fronteira no Brasil, no ano de 2004, surge como uma das ações da participação do Brasil no Mercado Comum do Sul (Mercosul) através da assinatura do Tratado de Assunção ${ }^{2}$, que declarou o português e o espanhol línguas oficiais do Mercosul.

Nesse interim, o Setor Educacional do Mercosul empreendeu ações para a difusão do português e do espanhol nos sistemas educacionais dos países membros, com o objetivo de fortalecer a identidade regional, a interculturalidade e contribuir para a melhoria da qualidade da educação, ações que envolveram pesquisas sobre a aquisição e aprendizagem de línguas e estudos sobre as fronteiras.

Após ações e reuniões entre os ministérios da educação dos países envolvidos, foram assinadas declarações conjuntas e elaborou-se a primeira versão do Projeto-piloto de Educação Bilingüie. Escolas de Fronteira Bilingües Português-Espanhol (doravante PEIBF³), em maio de $2004^{4}$.

O objetivo principal do PEIBF está ligado ao disposto na Declaração Conjunta assinada em Buenos Aires, em 2004, no âmbito da cooperação educacional entre Brasil e Argentina ${ }^{5}$ :

desenvolvimento de um modelo de ensino comum em escolas de zona de fronteira, a partir do desenvolvimento de um programa para a educação intercultural, com ênfase no ensino do português e do espanhol, uma vez cumpridos os dispositivos legais para sua implementação. (BRASIL, 2008, p.8)

Tendo como base a premissa presente no acordo entre os países, foram realizadas visitas técnicas a escolas da Região Sul do país que sinalizaram, por meio das secretarias municipais e estaduais de educação em comunicação com o Departamento de Políticas de Educação Infantil e do Ensino Fundamental, vinculado à Secretaria de Educação Básica do MEC. Em 2005, participavam do programa apenas duas escolas brasileiras nas cidades de Uruguaiana (RS) e Dionísio Cerqueira (SC) e duas escolas nas cidades argentinas Bernardo de Irigoyen (Misiones) e Paso de los Libres (Corrientes). Esse quadro de escolas foi ampliado no ano de 2006, sendo inseridas escolas, tanto do lado argentino quanto do lado brasileiro, nas cidades de Puerto Iguazú (Misiones), Santo Tomé e La Cruz (Corrientes), Foz do Iguaçu (PR), São Borja e Itaqui (RS).

Em 2008, foram incluídas escolas do Paraguai, do Uruguai e da Venezuela, ampliando o projeto para as cidades de Ponta Porã (MS), Jaguarão e Chuí (RS) e Pacaraima (RR), Pedro Juan Caballero (Paraguai), Rio Branco e Chuy (Uruguai) e Santa Elena de Uairén (Venezuela).

As especificidades das ações do PEIBF foram sendo desenhadas através de pesquisas desen-

20 acordo foi firmado em 1991 entre Brasil, Argentina, Uruguai e Paraguai.

3 O PEIBF se transformou no Programa Escolas Interculturais de Fronteira, instituído através da Portaria do MEC $n^{\circ} 798$, de 19 de junho de 2012.

${ }^{4}$ Informações coletadas no Documento Projeto Escola Intercultural Bilíngue de Fronteira (PEIBF). Disponível em: http://portal.mec.gov.br/escola-de-fronteira

${ }^{5}$ Convênio de Cooperação Educacional entre a República Argentina e a República Federativa do Brasil, subscrito em Brasília em 10 de novembro de 1997, e tendo presente o disposto no Memorando de Entendimento assinado em Buenos Aires em 6 de junho de 2003. 
volvidas por sociolinguístas, através do IPOL, que elaboraram instrumentos para traçar um diagnóstico sociolinguístico do trecho de fronteira onde estavam localizadas as escolas participantes do programa. Esse trecho da zona de fronteira foi estabelecido de acordo com a presença de cidades-gêmeas ${ }^{6}$, uma vez que a integração costuma ser maior nesse contexto.

Em estudo realizado por Sagaz (2013), a autora analisa o Projeto Escolas (interculturais) Bilíngues de Fronteira enquanto uma ação político linguística, por meio de dados coletados em pesquisas de campo e pelo Projeto Observatório da Educação na Fronteira (OBEDF). Nesse estudo a autora afirma que o desenvolvimento e implementação do PEIBF teve duas fases: a primeira entre 2004 e 2010 que contou com a assessoria do Instituto de Investigação e Desenvolvimento em Política Linguística (IPOL); a segunda entre 2011 e 2013 (ano de conclusão da pesquisa), quando as universidades federais assumiram as funções do IPOL e tece algumas críticas sobre o processo.

Uma das críticas feitas por Sagaz (2013, p. 116-117) diz respeito à gradação da inserção das séries do ensino fundamental no projeto, prevista para ocorrer anualmente com o objetivo de que em 2010 participassem alunos da $1^{\mathrm{a}}$ a $6^{\mathrm{a}}$ séries, no caso de escolas com 9 anos escolares, prazo médio para que todos os alunos estivessem estudando na segunda língua, o que não ocorreu, segundo a pesquisadora:

Em 2010 ainda não havia entendimentos pedagógicos, segundo relatoria, nem entre a Argentina e o Brasil e, nem entre o MEC e as escolas envolvidas para o avanço do Projeto. Também não havia estrutura operacional que pudesse viabilizar a participação das séries/anos finais. Em consequência, o processo de progressão estancou na $4^{a}$ série escolar. (SAGAZ, 2013, p. 117)

Além disso, apesar de estar em funcionamento desde 2004, apenas em 2012 o Documento Básico que orientava o projeto foi reescrito contendo as diretrizes do PEIBF, sendo denominado Modelo de enseñanza común en escuelas de zona de frontera a partir del desarrollo de un programa para la educación intercultural, con énfasis en la enseñanza de las lenguas predominantes en la región e disponibilizado apenas em espanhol pelo Mercosul Educacional ${ }^{7}$. (SAGAZ, 2013, p.117). Após essa remodelação, o programa teve seu nome alterado para Programa das Escolas Interculturais de Fronteira (PEIF), sendo regulamentado pela Portaria do MEC no 798/2012.

Nesse documento, que funcionou como um marco referencial para o desenvolvimento curricular das escolas de fronteira, é possível conhecer a estrutura, o funcionamento e as diretrizes pedagógicas utilizadas no PEIBF.

Conforme vimos anteriormente, o objetivo do PEIBF era o desenvolvimento de um modelo de ensino comum nas escolas de fronteira, possibilitando aos estudantes e professores uma educação e comunicação nas línguas dessas comunidades fronteiriças, tendo como base a implementação de um programa intercultural. ${ }^{8}$

Enquanto eram discutidas as diretrizes e a construção de um modelo (uma base curricular comum) e calendários a serem compartilhados entre as escolas ao longo da ampliação do programa,

\footnotetext{
${ }^{6}$ Cidades gêmeas participantes: Monte Caseros (Corrientes) - Barra do Quarai (RS); Paso de los Libres (Corrientes) - Uruguaiana (RS); La Cruz / Alvear (Corrientes) - Itaqui (RS); Santo Tomé (Corrientes) - São Borja (RS); San Javier (Misiones) - Porto Xavier (RS); Bernardo de Irigoyen (Misiones) - Dionísio Cerqueira (SC) / Barracão (PR); Puerto Iguazu (Misiones) - Foz do Iguaçu (PR). In: Documento Projeto Escola Intercultural Bilíngue de Fronteira (PEIBF). Disponível em: http://portal.mec.gov.br/escola-de-fronteira Acesso em 10 jan 2019.

7 Disponível em: https://docplayer.es/18210039-Escuelas-de-frontera-documento-marco-referencial-de-desarrollo-curricular.html Acesso em 17 fev 2019.

8 Descrito no documento Modelo de enseñanza común en escuelas de zona de frontera a partir del desarrollo de un programa para la educación intercultural, con énfasis en la enseñanza de las lenguas predominantes en la región (ARGENTINA; BRASIL, 2012).
}

https://periodicos.unifap.br/index.php/letras

Macapá, v. 10, n. 1, $1^{\circ}$ sem., 2020 
o projeto seguia os calendários e práticas em andamento nas escolas, de acordo com o sistema de ensino de cada país envolvido.

Baseados no intercâmbio docente (cruce de profesores) entre as escolas-espelho, a abordagem pedagógica do PEIBF seguia a metodologia de Ensino por Projetos de Aprendizagem $^{9}$ visando a construção de um modelo de ensino bilíngue e intercultural, no qual tanto o planejamento quanto a formação continuada dos professores deveria ser feita em conjunto.

Nesse sentido entra o conceito de cooperação interfronteiriça, descrita como uma maneira de superar as diversas visões negativas e restritivas impostas socialmente no que se refere ao termo fronteira, como espaço de separação, barreira, de preconceito com o outro que pertence ao "outro lado" da fronteira. Assim, segundo o modelo comum, a metodologia de ensino por projetos de aprendizagem funciona como um facilitador desse processo de cooperação interfronteiriça:

Além das reconhecidas vantagens pedagógicas do trabalho por projetos, desde o ponto de vista da cooperação interfronteiriça, o PEBF tem por objetivo permitir, organizar e fomentar a interação entre os agentes educativos e as comunidades educativas envolvidas, de forma a propiciar o conhecimento do outro e a superação de obstáculos nas relações com o saber e a interação com o colega. ${ }^{10}$ (ARGENTINA; BRASIL, 2012)

Entre os municípios partícipes do PEIBF, é possível observar que apenas um deles se localiza na Região Norte do Brasil, em Pacaraima, no estado de Roraima, e sua cidade-gêmea do lado venezuelano Santa Elena de Uairén. Tendo em vista esse contexto fronteiriço, Paz (2016) apresenta um estudo sobre a inclusão de estudantes venezuelanos em escolas municipais na cidade de Pacaraima, dando ênfase às escolas bilíngues de fronteira.

Em Pacaraima existem apenas 3 escolas na área urbana, as quais foram incluídas no PEIBF, duas no ano de 2009 e 1 no ano de 2014. Segundo Paz (2016), foram realizados diagnósticos sociolinguísticos, visitas a essas escolas, reuniões técnicas e seminários, no entanto, apesar dos esforços empreendidos, não foram implementadas as ações do PEIBF, devido à dificuldade em estabelecer cooperação com as escolas venezuelanas.

No Amazonas, segundo informações disponibilizadas pelo Centro de Formação Continuada, Desenvolvimento de Tecnologia e Prestação de Serviço para a Rede Pública de Ensino (CEFORT), da Universidade Federal do Amazonas, em sua página web ${ }^{11}$, ao longo do ano de 2015, o Programa Escolas Interculturais de Fronteira (PEIF) realizou um acompanhamento pedagógico em escolas do Alto Solimões, nas cidades de Benjamin Constant e Tabatinga, que culminou no Seminário Experiências significativas em sala de aula, onde foram apresentadas as principais ações desenvolvidas pelas escolas na busca pelo desenvolvimento do ensino-aprendizagem desde a perspectiva intercultural. Porém, assim como em Roraima, não houve a implementação efetiva do programa nas escolas, uma vez que as verbas foram suspensas desde o ano de 2016 pelo Governo Federal ge-

9“En la perspectiva de la Enseñanza Via Proyectos de Aprendizaje (EPA) los niños participan de proyectos bilingües que prevén tareas a ser realizadas en las lenguas, 22 coordinadas por los docentes, de acuerdo con el nivel de conocimiento del idioma que posean y de acuerdo con la planificación conjunta realizada periódicamente. Los proyectos, por lo tanto, son bilingües: el alumno realiza determinadas actividades en L1 y otras en la L2, pero todas ellas confluyen en un objetivo común, que es el de producir respuestas y mayor comprensión a partir de una problemática central determinada de antemano". (ARGENTINA; BRASIL, 2012)

10 Original: "Además de las reconocidas ventajas pedagógicas del trabajo por proyectos, desde el punto de vista de la cooperación interfronteriza, el PEBF tiene por objetivo permitir, organizar y fomentar la interacción entre los agentes educativos y las comunidades educativas involucradas, de manera tal de propiciar el conocimiento del otro y la superación de obstáculos en las relaciones con el saber y con la interacción con el colega". (ARGENTINA; BRASIL, 2012)

11 Disponivel em: http://www.cefort.ufam.edu.br/portal/index.php?option=com_content\&view=article\&id= $387 \&$ catid=43\&ltemid=54 Acesso em 17 fev 2019.

https://periodicos.unifap.br/index.php/letras

Macapá, v. 10, n. 1, $1^{\circ}$ sem., 2020 
rando a descontinuidade do funcionamento do PEIBF.

Na perspectiva do PEIBF, em 2011 foi criado o Observatório da Educação na Fronteira (OBEDF), tendo como base metodológica uma pesquisa-ação, seu objetivo principal estava vinculado a uma percepção política de valorização das línguas no processo de alfabetização dos anos escolares iniciais em escolas localizadas na faixa de fronteira dos estados do Acre, Rondônia, Mato Grosso do Sul e Paraná, nas fronteiras com Paraguai e Bolívia. (MORELLO, 2016)

Desta forma, percebemos que apesar da importância de um projeto como o PEIF para as línguas em contexto de fronteira, não houve por parte do Estado o interesse em sua manutenção e ampliação. O que ocorreu e ocorre no país é a descontinuidade das políticas linguísticas propostas, como foi, por exemplo, o caso da revogação da Lei 11.161/2005, que regulamentava a oferta da língua espanhola nas escolas brasileiras.

É importante destacar que apesar da descontinuidade do programa, instituições como a Universidade da Integração Latino-Americana (UNILA) deram continuidade a ações que buscam o fortalecimento dessa integração, com a criação do Programa Pedagogia Intercultural que tem como objetivo oferecer uma formação permanente em línguas estrangeiras nas escolas de ensino fundamental, tanto para os estudantes como para os professores, da cidade de Foz do Iguaçu, por meio de um acordo de cooperação técnica entre a UNILA e a Secretaria Municipal de Educação. ${ }^{12}$

Nas palavras de Paz (2016, p.81-82) é possível observar a importância da escola intercultural de fronteira e das línguas na formação social dos habitantes desse espaço:

Percebeu-se que o caminho para a inclusão social na fronteira é a escola. A escola na fronteira entre o Brasil e a Venezuela é visto como um território de trégua, onde "o outro", não é percebido como "o outro" e onde "o outro", não se sente como indivíduo do outro lado da fronteira, tornando-se um ambiente sagrado onde impera a tolerância, o bom convívio, o conhecimento, a valorização e a reprodução das duas culturas, com práticas de interação e de diálogo, em ambos idiomas no cotidiano escolar.

Em estudos recentes realizados por grupos de trabalho designados pelo Ministério da Integração Nacional e o Instituto de Pesquisa Econômica e Aplicada (IPEA), ligados à pesquisa Fronteiras do Brasil: uma avaliação de política pública, foram divulgadas as principais conclusões e sugestões sobre as fronteiras da Região Norte no livro Fronteiras do Brasil: uma avaliação do arco norte (volume 3), lançado em 2018.

Entre as conclusões está algo levantado por Paz (2016) na citação anterior, a questão da interação e do diálogo nos dois idiomas na escola, uma vez que segundo a comissão que realizou entrevistas e estudos de campo em Boa Vista e nas cidades fronteiriças com a Guiana e a Venezuela, no ano de 2015, um dos problemas constatados reside na ausência de escolas binacionais e cursos de línguas estrangeiras, visto que, durante o estudo, foi detectada a dificuldade de interação e comunicação devido a um tratamento inadequado das línguas na faixa de fronteira ${ }^{13}$.

Observamos a necessidade de uma gestão das línguas por parte do Estado, compreendendo a gestão de línguas desde a perspectiva de Spolsky (2004, p.11):

O gerenciamento da linguagem refere-se à formulação e à proclamação de um planejamento ou política explícita, geralmente, mas não necessariamente escrito em um documento formal, sobre o uso da linguagem. Como veremos, a existência de tal política explícita não garante que ela será implementada, nem a implementação garante sucesso. ${ }^{14}$

12 Disponível em: https://documentos.unila.edu.br/convenio/38/2018 e publicado no D.0.U em 04 dez 2018.

13 PÊGO (coord.) (et al). Fronteiras do Brasil: uma avaliação do Arco Norte. Rio de Janeiro: IPEA, MI, 2018. $296 \mathrm{p}$.

14 Tradução da autora: “Language management refers to the formulation and proclamation of an explicit plan 
A gestão das línguas é considerada por Spolsky (2004) como um dos três elementos da Política Linguística (juntamente com as práticas linguísticas e as crenças e ideologias linguísticas), sendo de suma importância considerar diversos fatores para a construção de propostas de planejamento das línguas segundo o diagnóstico da situação linguística detectada.

Sendo assim, observamos a urgência de uma regulamentação na legislação que vise dar respaldo às políticas linguísticas e educacionais nos diversificados contextos das fronteiras brasileiras, de norte a sul, bem como uma política de relações exteriores que priorize os acordos com os países vizinhos com o objetivo de estreitar os laços culturais e linguísticos que nos une e nos separa, ao mesmo tempo.

Essa política in vitro desenvolvida pelo Estado deve ter como premissa a participação da comunidade de falantes, uma vez que o planejamento e políticas desenvolvidas deverão ser pensadas e elaboradas considerando os fenômenos in vivo, ou seja, pensar as políticas linguísticas na fronteira requer conhecer seu entorno linguístico, o peso das línguas nos contextos em que são utilizados e seu valor simbólico junto aos falantes, reconhecendo os repertórios linguísticos, as crenças e ideologias sobre as línguas construídas e presentes no imaginário desses falantes.

Assim, a gestão das línguas não deve estar desvinculada dos seus falantes, de sendo uma ação de cima para baixo, mas de forma integrada, como propõem Oliveira e Altenhofen (2011, p.14):

a) a importância da participação dos falantes na gestão de suas línguas, daí a priorização de ações in vivo;

b) o reconhecimento da pluralidade e da interdisciplinaridade como princípios de uma educação de qualidade e de uma democracia cultural;

c) a necessidade de ações de conscientização linguística (language awareness) para orientar as decisões dos falantes;

d) a relevância de incluir a discussão da educação linguística e plurilíngue no modelo de escola e de sociedade que se deseja.

O Programa Escolas Interculturais (bilíngues) de Fronteira buscou contemplar essa política in vivo, dando um importante passo rumo à integração latino-americana, porém acredito que a necessidade de ampliação desse projeto passa pela ideia de conceber não apenas o par linguístico português-espanhol, mas todas as línguas que fazem parte do universo dessas comunidades, configurando a existência de escolas interculturais plurilíngues de fronteira, amparadas por uma legislação transnacional que possa configurar uma cooperação entre os países nas fronteiras.

Atualmente, a Organização dos Estados Ibero-americanos em cooperação com o Ministério de Educação do Brasil, de Portugal e da Espanha lançou, no ano de 2018, o Programa IberoAmericano de Difusão da Língua Portuguesa, cujo objetivo principal é:

potencializar o uso da língua portuguesa num modelo bilíngue junto com o espanhol na região Ibero-americana, ampliando os espaços políticos, educativos, culturais, convertendo a OEI numa organização essencialmente bilíngue e de referência na região. (OEI, 2019, p.64)

O projeto se assemelha ao extinto PEIBF/PEIF ao propor a criação de escolas de fronteira com modelo de ensino comum e a mobilidade e o intercâmbio de profissionais da educação e da cultura, além da proposição de ações coordenadas entre as escolas situadas nos países fronteiriços.

Farão parte do projeto piloto as seguintes cidades:

or policy, usually but not necessarily written in a formal document, about language use. As we will see, the existence of such an explicit policy does not guarantee that it will be implemented, nor does implementation guarantee success".

https://periodicos.unifap.br/index.php/letras

Macapá, v. 10, n. 1, $1^{\circ}$ sem., 2020 
Tabela 2: Cidades contempladas na fase piloto do Programa Ibero-Americano de Difusão da Língua Portuguesa

\begin{tabular}{|l|l|}
\hline Fronteira Brasil-Uruguai & $\begin{array}{l}\text { Chuí-Chuy } \\
\text { Livramento-Rivera }\end{array}$ \\
\hline Fronteira Brasil-Argentina & Bernardo de Irigoyen-Dionísio Cerqueira-Barracão \\
\hline Fronteira Brasil-Argentina-Paraguai & Foz do Iguaçu-Puerto Iguazu-Ciudad del Este \\
\hline Fronteira Brasil-Paraguai & $\begin{array}{l}\text { Mundo Novo-Guaíra-Salto del Guairá } \\
\text { Paranhos-Ype Jhu } \\
\text { Coronel Sapucaia-Capitán Bado } \\
\text { Ponta Porã-Pedro Juan Caballero }\end{array}$ \\
\hline Fronteira Brasil-Bolívia & $\begin{array}{l}\text { Corumbá-Puerto Suarez } \\
\text { Guajara-Mirim-Guayaramerin }\end{array}$ \\
\hline Fronteira Brasil-Colômbia & Tabatinga -Letícia \\
\hline Fronteira Brasil-Peru & Benjamin Constant-Islândia \\
\hline Fronteira Portugal-Espanha & Em avaliação \\
\hline
\end{tabular}

Como é possível observar na tabela acima, apenas dois territórios fronteiriços localizados na região norte do Brasil foram contemplados no projeto da OEI, levantando a urgência de uma discussão voltada para a necessidade da criação e de legislação que regulamente políticas públicas voltadas para a educação em contexto fronteiriço e, consequentemente, para a gestão do plurilinguismo nesses territórios.

\section{CONSIDERAÇÕES FINAIS}

Urge discutir ações em políticas linguísticas voltadas para as línguas nas zonas de fronteira do Brasil, de modo que foram apresentadas considerações sobre o Programa Escolas Interculturais de Fronteira, em parceria entre o Ministério de Educação do Brasil e dos demais países integrantes do Mercosul.

Ficou clara a importância do programa para essas regiões que sempre foram e continuam sendo negligenciadas e invisibilizadas pelo Estado no que concerne a criação e manutenção políticas que levem em consideração os diversos aspectos que caracterizam socialmente as comunidades que vivem nas fronteiras.

Assim, foi possível observar, através de vários estudos sobre as fronteiras em diferentes áreas do conhecimento, a necessidade de se pensar políticas que busquem a integração transfronteiriça e que o espaço mais adequado para desenvolver essa consciência é a escola com a confluência dos diversos saberes e experiências culturais e linguísticas que são o reflexo dessas comunidades.

Desta forma, faz-se necessário pensar possíveis soluções para a gestão das línguas nas fronteiras, que passam desde a reformulação da legislação a ações locais:

a) Inclusão das escolas de fronteira e suas particularidades na legislação brasileira que regulamenta a educação básica no país;

b) Ampliação do Programa Escolas Interculturais de Fronteira para as demais regiões do país;

c) Fortalecimento das relações com os países vizinhos para a construção de políticas educacionais transnacionais no contexto fronteiriço;

d) Realização de diagnóstico sociolinguístico junto às comunidades nas regiões de fronteira não contempladas na primeira fase do PEIF;

e) Criação de acordos de cooperação entre universidades e redes municipais e estaduais de educação para o planejamento de políticas in vitro com base nas situações in vivo detectadas, incluindo a formação continuada dos docentes e gestores das escolas;

f) Abertura da escola à comunidade, através de projetos que visem a integração e difusão do plurilinguismo como contribuição para o desenvolvimento local, como por exemplo, a oferta de cursos de línguas para os habitantes de ambos os lados das fronteiras.

Destarte, é indiscutível a importância da manutenção e ampliação do Programa Escolas Interculturais de Fronteira, onde não apenas as línguas oficiais dos países envolvidos estejam presen- 
tes na sala de aula, mas que todos possam se sentir representados e possam compartilhar e construir seus repertórios linguísticos rumo a uma sociedade cada vez mais plurilíngue e longe das barreiras linguísticas construídas através dos séculos de negação e glotocídio impostos através da visão conservadora do Brasil como uma nação monolíngue.

\section{REFERÊNCIAS}

ARGENTINA; BRASIL. Ministério da Educação; Ministerio de Educación, Ciencia y Tecnología. Escolas de Fronteira. Programa Escolas Bilíngües de Fronteira. Brasília; Buenos Aires, mar. 2008. Disponível em: http://portal.mec.gov.br/seb/arquivos/pdf/Escolafronteiras/doc_final.pdf Acesso em 10 jan 2019

ARGENTINA, BRASIL. Programa Escuelas Interculturales Bilíngües De Frontera (PEBF): "Modelo de enseñanza común en escuelas de zona de frontera a partir del desarrollo de un programa para la educación intercultural, con énfasis en la enseñanza de las lenguas predominantes en la región": Brasília; Buenos Aires, 2012. Disponível em: https://docplayer.es /18210039-Escuelas-de-frontera-documento-marco-referencial-de-desarrollo-curricu-

lar.html Acesso em 17 fev 2019

BERGER, Isis R. Gestão do multi/plurilinguismo em escolas brasileiras na fronteira brasil - Paraguai: um olhar a partir do Observatório da Educação na Fronteira. Tese (Doutorado em Linguística) Universidade Federal de Santa Catarina, Florianópolis, 2015.

CALVET, Louis-Jean. Sociolinguística: uma introdução crítica. São Paulo: Parábola, 2002.

CEFORT. PEIF conclui atividades de 2015 Seminário "Experiências Significativas na Sala de Aula". Disponível em: http://www.cefort.ufam.edu.br/portal/index.php?option=com_content\&view $=$ article\&id $=387 \&$ catid $=43 \&$ Itemid $=54$ Acesso em 05 fev 2019 .

LUNA, Cláudia. A cidade ideal: fronteiras reais/ fronteiras simbólicas. Disponível em: http://www.letras.ufrj.br/neolatinas/media/publicacoes/cadernos/a4n3/claudia_luna.pdf

Acesso em 20 jun 2018.

MORELLO, Rosângela. Línguas, Fronteiras e Perspectivas para o Ensino Bilíngue e Plurilíngue no Brasil In: MORELLO; Rosângela; MARTINS, Marci F. (orgs.) Política Linguística em Contextos Plurilíngues: Desafios e Perspectivas para a Escola. IPOL, Florianópolis: Ed. Garapuvu, 2016. p.17-44.

OEI. Programa de Difusão da Língua Portuguesa. $77^{a}$ Reunião Ordinário do Conselho Consultivo da Organização dos Estados Ibero-Americanos, Antígua, 2018.

OLIVEIRA, Gilvan M. de. Política Linguística, Política Historiográfica: epistemologia e escrita da história da(s) língua(s) a propósito da língua portuguesa no Brasil Meridional (1754 - 1830). 2004. 230 f. Tese (Doutorado em Linguística) - Instituto de Estudos da Linguagem da Universidade Estadual de Campinas, Campinas, 2004.

OLIVEIRA, Gilvan M. de; ALTENHOFEN, Cléo V. . O in vitro e o in vivo na política da diversidade lingüística do Brasil: inserção e exclusão do plurilingüismo na educação e na sociedade. In: MELLO, Heliana; ALTENHOFEN, Cléo V.; RASO, Tommaso. (Org.). Os contatos linguísticos no Brasil. 1ed. Belo Horizonte: Editora UFMG, 2011, v. , p. 187-216.

PAZ, Sandra E. T. Escolas bilíngues de fronteira: inclusão de discentes venezuelanos nas escolas municipais da área urbana de Pacaraima. 2016. 96 f. Dissertação (Mestrado em Sociedade e Fronteira) - Universidade Federal de Roraima, Boa Vista, 2016. (Dissertação)

PÊGO (coord.) (et al). Fronteiras do Brasil: uma avaliação do Arco Norte. Rio de Janeiro: IPEA, MI, 2018. 296 p.

SAGAZ, Márcia R. P., Projeto Escolas (Interculturais) Bilíngues de Fronteira: análise de uma ação político linguística. Dissertação (Mestrado em Linguística) - Universidade Federal de Santa Catarina: Florianópolis, 2013.

SPOLSKY, Bernard. Language Policy. In: COHEN, James et al. Procedings of the 4th Interna- 
tional Symposium on Bilingualism. Somerville, MA: Cascadilla Press, 2005. p. 2152 2164. Disponível em: <http://www.lingref.com/isb/4/168ISB4.PDF>. Acesso em: 28 mai. 2012. 